\title{
Lactate clearance as a prognostic marker of mortality in severely ill febrile children in East Africa
}

\author{
A. Aramburo ${ }^{1}$, Jim Todd ${ }^{2}$, Elizabeth C. George ${ }^{3}$, Sarah Kiguli ${ }^{4}$, Peter Olupot-Olupot ${ }^{5,6}$, Robert O. Opoka ${ }^{4}$, \\ Charles Engoru', Samuel O. Akech ${ }^{8}$, Richard Nyeko ${ }^{9}$, George Mtove ${ }^{10}$, Diana M. Gibb ${ }^{3}$, Abdel G. Babiker ${ }^{3}$ \\ and Kathryn Maitland ${ }^{8,11^{*}}$
}

\begin{abstract}
Background: Hyperlactataemia $(\mathrm{HL})$ is a biomarker of disease severity that predicts mortality in patients with sepsis and malaria. Lactate clearance (LC) during resuscitation has been shown to be a prognostic factor of survival in critically ill adults, but little data exist for African children living in malaria-endemic areas.

Methods: In a secondary data analysis of severely ill febrile children included in the Fluid Expansion as Supportive Therapy (FEAST) resuscitation trial, we assessed the association between lactate levels at admission and LC at $8 \mathrm{~h}$ with all-cause mortality at $72 \mathrm{~h}$ (d72). LC was defined as a relative lactate decline $\geq 40 \%$ and/or lactate normalisation (lactate $<2.5 \mathrm{mmol} / \mathrm{L}$ ).

Results: Of 3170 children in the FEAST trial, including 1719 children (57\%) with Plasmodium falciparum malaria, 3008 (95\%) had a baseline lactate measurement, 2127 (71\%) had HL (lactate $\geq 2.5 \mathrm{mmol} / \mathrm{L}$ ), and 1179 (39\%) had severe HL ( $\geq 5$ mmol/L). Within 72 h, 309 children (10.3\%) died, of whom 284 (92\%) had baseline HL. After adjustment for potential confounders, severe HL was strongly associated with mortality (Odds Ratio (OR) 6.96; 95\% Cl 3.52, 13.76, $p<0.001)$. This association was not modified by malaria status, despite children with malaria having a higher baseline lactate (median $4.6 \mathrm{mmol} / \mathrm{L}$ vs $3 \mathrm{mmol} / \mathrm{L} ; p<0.001)$ and a lower mortality rate $(\mathrm{OR}=0.42 ; p<0.001)$ compared to non-malarial cases. Sensitivity and specificity analysis identified a higher lactate on admission cut-off value predictive of $\mathrm{d} 72$ for children with malaria $(5.2 \mathrm{mmol} / \mathrm{L})$ than for those with other febrile illnesses $(3.4 \mathrm{mmol} / \mathrm{L})$.

At 8 h, 2748/3008 survivors (91\%) had a lactate measured, 1906 (63\%) of whom had HL on admission, of whom 1014 (53\%) fulfilled pre-defined LC criteria. After adjustment for confounders, LC independently predicted survival after $8 \mathrm{~h}$ $(\mathrm{OR} 0.24 ; 95 \% \mathrm{Cl} 0.14,0.42 ; p<0.001)$. Absence of $\mathrm{LC}(<10 \%)$ at $8 \mathrm{~h}$ was strongly associated with death at $72 \mathrm{~h}$ (OR 4. $62 ; 95 \% \mathrm{Cl} 2.7,8.0 ; p<0.001)$.
\end{abstract}

Conclusions: Independently of the underlying diagnosis, $\mathrm{HL}$ is a strong risk factor for death at $72 \mathrm{~h}$ in children admitted with severe febrile illnesses in Africa. Children able to clear lactate within $8 \mathrm{~h}$ had an improved chance of survival. These findings prompt the more widespread use of lactate and LC to identify children with severe disease and monitor response to treatment.

Trial registration: ISRCTN69856593 Registered 21 January 2009.

Keywords: Hyperlactataemia, Children, Lactate clearance, East Africa, Mortality, Hospital admission, Clinical trials, Randomised, Sepsis, Malaria

\footnotetext{
* Correspondence: k.maitland@imperial.ac.uk

${ }^{8}$ Kilifi Clinical Trials Facility, KEMRI-Wellcome Trust Research Programme, PO

Box 203, Nairobi, Kenya

${ }^{11}$ Department of Paediatrics, Faculty of Medicine, Imperial College, W2 1PG,

London, UK

Full list of author information is available at the end of the article
} 


\section{Background}

Infection is a leading cause of death in children under 5 years of age in resource-poor countries in Africa, mainly related to pneumonia, diarrhea, and malaria [1]. Irrespective of the underlying aetiology, children with severe infection in these settings usually present critically ill to health units with basic facilities, with most deaths occurring within the first $24 \mathrm{~h}$ of admission [2]. Immediate recognition and prompt appropriate resuscitation of those children at highest risk of death are crucial to improve survival. Clinical criteria have been proposed by the World Health Organization (WHO) [3, 4], and practical clinical bedside risk scores have been evaluated to identify those at greatest risk of death [5]; however, data on point-of-care diagnostics to refine and target management at the point of triage are still lacking.

Hyperlactataemia (HL) is a well-known biomarker of severe disease that strongly predicts death in paediatric and adult patients with bacterial sepsis and malaria [6-9]. Its prognostic value, availability of point-of-care non-invasive testing, and immediate turnaround time have made lactate measurement one of the most widely recommended tools for early recognition and risk stratification of patients with severe sepsis [10-12]. In malaria-endemic areas, however, the use of point-ofcare lactate measurement is controversial due to lack of data to support wider implementation $[5,13]$. Nevertheless, therapeutic strategies aimed at decreasing lactataemia in serial determinations of lactate clearance (LC) could be a simple tool and may be clinically more valuable than initial single lactate measurements, helping to guide resuscitation and potentially being a costeffective measure in these settings.

In recent years, several studies including two metaanalyses have demonstrated that early LC and lactate normalisation are powerful independent predictors of survival in critically ill adults [14-17]. Furthermore, two randomised clinical trials $[18,19]$ showed that targeting initial treatment to a pre-specified LC was associated with non-inferior or even superior outcomes compared to central venous oxygen saturation, a surrogate marker of cardiac output and a standard invasive therapeutic goal in sepsis. To date, however, only a few small studies have explored the prognostic value of LC in severely ill children with sepsis or malaria [20-22]. A large multicentre randomised control trial of fluid resuscitation strategies in severely ill febrile children in east Africa, the Fluid Expansion as Supportive Therapy (FEAST) trial, ISRCTN69856593 [23], provided a good opportunity to explore this question further.

The main aim of the current study was to assess the prognostic value of LC at $8 \mathrm{~h}$ on all-cause mortality at $72 \mathrm{~h}(\mathrm{~d} 72)$ in a large cohort of severely ill febrile children in a malaria-endemic area. Secondary aims were to confirm the association between HL and $\mathrm{d} 72$, assess if this was modified by type of severe febrile illness (malaria vs non-malaria), and to determine the cut-off lactate level on admission that best predicts mortality in these children.

\section{Methods}

The current study is a secondary analysis derived from the FEAST trial [23]. The overall aim of the trial was to answer whether rapid expansion of intravascular volume was safe and improved survival compared to no bolus (maintenance only). The study was conducted between January 2009 and January 2011 at six clinical centres, including large regional and district hospitals in three east African countries (Kilifi, Kenya; Muheza, Tanzania; and Kampala, Mbale, Soroti, and Lacor in Uganda). Malaria transmission in Kilifi and Muheza was predominantly seasonal and of moderate intensity during the period of the trial, whilst transmission at all sites in Uganda was perennial and intense.

\section{Study population}

Children were eligible for the FEAST trial if they were between 60 days and 12 years of age, had a history of fever and/or abnormal temperature (pyrexia $\left[\geq 37.5^{\circ} \mathrm{C}\right]$ or hypothermia $\left[<36{ }^{\circ} \mathrm{C}\right]$ ), and were admitted to hospital with severe illness (respiratory distress and/or impaired consciousness) plus at least one of the following signs of impaired peripheral perfusion: capillary refill time $>2$ s; lower limb temperature gradient (defined as a notable temperature change from cold [dorsum of foot] to warm [knee] when running the back of the hand from the toe to the knee); weak radial pulse; or severe tachycardia (defined as heart rate $>180$ beats per minute [bpm] for children $<1$ year old, $>160 \mathrm{bpm}$ for those 1 to 4 years old, > $140 \mathrm{bpm}$ for those $\geq 5$ years old). Children were excluded from the trial if they presented with severe acute malnutrition, gastroenteritis, burns, or surgical conditions. Children were randomised to receive immediate boluses of $20-40 \mathrm{~mL} / \mathrm{kg}$ of $5 \%$ human albumin solution or $0.9 \%$ saline solution over $1 \mathrm{~h}$ (intervention group) following by maintenance fluids, or maintenance intravenous fluids only at $4 \mathrm{~mL} / \mathrm{kg} / \mathrm{h}$ (control group) until able to drink. The primary endpoint was mortality at $48 \mathrm{~h}$ after randomisation.

\section{Clinical care}

Standardised case report forms were completed at enrolment and at specific time points during the first $48 \mathrm{~h}$. At enrolment, lactate, haemoglobin, and glucose point-ofcare measurements were conducted, together with an HIV antibody test, malaria blood film, and a rapid diagnostic test for malaria. At $8 \mathrm{~h}$ and $24 \mathrm{~h}$, lactate and haemoglobin measurements were repeated. Lactate was 
measured using a Lactate Pro $^{\circ}$ (Arkray KDK, Kyoto, Japan) hand-held analyser, which was calibrated daily, and each time a new box of Lactate $\mathrm{Pro}^{\circ}$ Test Strips was used. The test results, available in $60 \mathrm{~s}$, displayed 'LO' if the lactate level was below $0.8 \mathrm{mmol} / \mathrm{L}$ and ' $\mathrm{HI}$ ' if the lactate level was above $23.3 \mathrm{mmol} / \mathrm{L}$. Out-of-range results were repeated for verification. Haemoglobin was determined with the HemoCue ${ }^{\circ} \mathrm{Hb} 301$ system, Angelholm, Sweden. Children were managed on general paediatric wards, with no facilities for ventilation other than short-term 'bag-and-mask' support. Training in triage, identification, and definitions of adverse events related to fluid management (including transfusion) was given prior to and throughout the trial and was included in the trial manual of operations that was given to every team member. The main outcome of the FEAST trial [23] and the transfusion practices [24] used in the study have been reported in detail previously.

\section{Statistical analysis}

The current secondary analysis was performed using the parent study database, cleaned and exported into STATA version 11 (StataCorp, LP, College Station, TX, USA). All children in the FEAST dataset with a valid lactate measurement at time of admission were included in the analysis, with a subsequent analysis of those who also had a lactate measurement $8 \mathrm{~h}$ after admission.

\section{Hyperlactataemia classification and lactate clearance definition}

In the current study, we considered HL as a lactate $>2.5$ $\mathrm{mmol} / \mathrm{L}$. We sub-categorised patients according to the lactate level on hospital admission as having moderate HL (lactate 2.5 to $<5 \mathrm{mmol} / \mathrm{L}$ ), severe $\mathrm{HL}$ (lactate $\geq 5$ $\mathrm{mmol} / \mathrm{L}$ ), or no $\mathrm{HL}$ (lactate $<2.5 \mathrm{mmol} / \mathrm{L}$ ). An $\mathrm{LC}$ value was calculated for all children with an increased lactate level on admission $(\geq 2.5 \mathrm{mmol} / \mathrm{L})$ who were alive and had a lactate measurement at $8 \mathrm{~h}$. Relative LC (percent) was defined by the equation [(lactate initial - lactate at 8 h)/lactate initial] $\times 100$, for which lactate initial was the measurement at randomisation. Lactate normalisation was defined as a lactate decline to $<2.5 \mathrm{mmol} / \mathrm{L}$ at $8 \mathrm{~h}$. The 8-h LC goal was defined by a relative lactate decrease of at least $40 \%$ from baseline and/or lactate normalisation.

Baseline clinical characteristics by survival status were described, combining randomisation groups. Frequencies and percentages were used for categorical variables, and medians with their inter-quartile range (IQR) for nonnormally distributed continuous data. Baseline clinical characteristics were compared across outcome categories using the chi-squared test or the Wilcoxon signedrank test as appropriate. Descriptive analysis reported both missing and available data.
The main exposure of interest was LC at $8 \mathrm{~h}$. The primary outcome was all-cause in-hospital mortality at $72 \mathrm{~h}$ of randomisation (d72). As a first step in the LC analysis, the association between baseline HL and d72 was examined. For each of the exposures, HL and LC, the crude odds ratio (OR) with 95\% confidence interval (CI) was calculated for the association with d72. To identify potential confounders, associations between patient characteristics and exposure and outcome variables were determined. Classic Mantel-Haenszel methods were used to explore for confounding and effect modification. A multivariable logistic regression model was fitted with a stepwise forward process selection to estimate the OR adjusted for several covariates simultaneously using all available data. Candidate variables were selected using previously defined risk factors of mortality and confounders identified in the univariate analysis. Age, sex, and study site were included $a$ priori in both models due to their association with a wide range of health parameters. The effect of the trial intervention was included as a potential confounder and tested as an effect modifier of the association between LC and $\mathrm{d} 72$ with increased mortality in the FEAST trial. Likelihood ratio tests were used to assess for the model fit.

Receiver operating characteristic (ROC) curve analysis was used to determine the cut-off value for lactate level at hospital admission that would best predict death at 72 h. As children with malaria had a higher prevalence of severe HL despite a lower mortality rate, ROC curves were also built separately for children with and without malaria to assess if the best prognostic cut-offs differed (Fig. 1). A ROC curve was also fitted for $\mathrm{d} 72$ based on the regression model for LC at $8 \mathrm{~h}$.

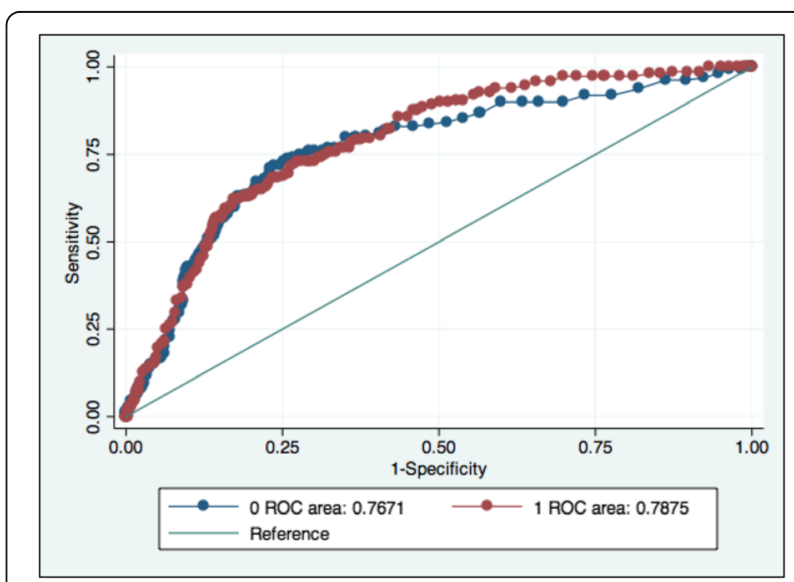

Fig. 1 ROC curve for mortality at $72 \mathrm{~h}$ of randomisation based on lactate measurement at admission by malaria: $0=$ no malaria and $1=$ malaria 


\section{Results}

Of 3170 children randomised in the FEAST trial, 3008 (95\%) had a lactate measurement on hospital admission and were included in the current analysis. In this group, there were 309 deaths $(10.3 \%)$ in the first $72 \mathrm{~h}$ after randomisation, which accounted for $90 \%$ of the overall mortality by 28 days. The clinical and laboratory baseline characteristics of the children by primary outcome are summarised in Table 1 . The median age was 24 months (IQR 13 to 39), and 1387 (46\%) were female. The majority of children presented with respiratory distress (2463, $82 \%$ ) and/or impaired consciousness (2326, 78\%). All had at least one sign of impaired perfusion, including severe tachycardia (2120,71\%), a prolonged capillary refilling time of $2 \mathrm{~s}$ or longer $(2030,67 \%)$, or a lower limb temperature gradient $(1777,59 \%)$. Weak radial pulse volume, present in 635 children (21\%) and bradycardia (in 36 children) were strongly associated with a poor outcome (unadjusted OR 4.24; 95\% CI 3.30, 5.45; $p<$ 0.001 and 13.13 ; 95\% CI 6.62, 26; $p<0.001$ respectively). Severe anaemia $(\mathrm{Hb}<5 \mathrm{~g} / \mathrm{dL})$ was present in 958 children (33\%) at admission. Plasmodium falciparum malaria was confirmed in 1719 children (57\%) and HIV infection in 106 (4\%) of the 2417 children tested. A blood culture was positive in 123 (12\%) of the 1052 children in whom the test was performed.

\section{Baseline lactate level and mortality}

At hospital admission 2127 children (71\%) had a raised baseline lactate $(\geq 2.5 \mathrm{mmol} / \mathrm{L})$. Of these, 948 children (32\%) had moderate HL (lactate 2.5 to $<5 \mathrm{mmol} / \mathrm{L}$ ) and 1179 (39\%) had severe HL (lactate $\geq 5 \mathrm{mmol} / \mathrm{L}$ ). Children with severe HL had a higher prevalence of other clinical and laboratory markers of disease severity, including hypoxaemia $\left(S_{\mathrm{p}} \mathrm{O}_{2}<90 \%\right.$ by pulse oximetry) ( $p<$ $0.001)$, coma $(p<0.001)$, severe anaemia $(p<0.001)$, or severe acidosis $(p<0.001)$. Children with malaria parasitaemia had higher mean baseline lactate (4.6 vs 3 $\mathrm{mmol} / \mathrm{L}, p<0.001)$ and prevalence of severe HL (46\% vs $30 \%, p<0.001)$ than those with other febrile illnesses.

Of the 309 children who died in the first $72 \mathrm{~h}, 238$ (77\%) had severe HL on admission and 46 (15\%) had moderate HL. The median admission lactate in children who died was significantly higher $(10.9 \mathrm{mmol} / \mathrm{L}$; IQR 5.2-13.6) than in those who survived the first $72 \mathrm{~h}(3.4$ $\mathrm{mmol} / \mathrm{L}$; IQR 2.2-6.9) $(p<0.001)$. Amongst those children who died, the median admission lactate was higher when death occurred in the first $8 \mathrm{~h}(12.2 \mathrm{mmol} / \mathrm{L}$; IQR 8.6-13.9) than when it occurred between 8 and $72 \mathrm{~h}$ (7.65 mmol/L; IQR 4.1-12.6) or after $72 \mathrm{~h}(3.2 \mathrm{mmol} / \mathrm{L}$; IQR 2.1-5.2) of the admission respectively.

In the univariate analysis, baseline severe HL strongly increased the odds of death at $72 \mathrm{~h}$ (OR 8.66; 95\% CI $5.7,13.2)$, whilst moderate HL had a weaker effect on mortality (OR 1.75; 95\% CI 1.06, 2.87). This association did not significantly vary amongst children with and without malaria, indicating that severe HL was equally prognostic for both conditions. Evidence for an effect modification, however, was found between HL and hyperglycaemia (glucose $\geq 8.3 \mathrm{mmol} / \mathrm{L}$ ) (heterogeneity test $p<0.01$ ), elevated blood urea nitrogen (BUN) (heterogeneity test $p<0.001$ ), and presence of crackles on auscultation (heterogeneity test $p=0.025$ ) (Additional file 1: Supplementary tables).

After full adjustment for confounders (Table 2), severe $\mathrm{HL}$ on hospital admission remained strongly associated with death at $72 \mathrm{~h}$ (OR 6.96; 95\% CI 3.52, 13.76), whilst moderate HL showed a weaker association (OR 1.57; 95\% CI 0.80, 3.08).

Coma was a strong independent risk factor (OR 6.87; 95\% CI 3.36, 14.04), and elevated BUN and HIV infection were moderately strong independent risk factors of death identified in the model. Whilst a positive malaria test appeared to be more strongly associated with higher likelihood of survival, this cannot be interpreted as a protective effect of parasitaemia per se, since the model was controlling for other factors which are likely impacted by malaria and strongly associated with mortality.

The multivariable regression model accounting for the interaction between $\mathrm{HL}$ and hyperglycaemia demonstrated a weakened association between HL and mortality in the presence of hyperglycaemia (OR 3.22; 95\% CI $1.56,6.67 ; p<0.01)$, although the effect of HL on the risk of mortality in the absence of hyperglycaemia (OR 8.55; 95\% CI 4.63, 15.78; $p<0.001$ ) was slightly greater. Furthermore, logistic regression analysis accounting for the additional interactions identified demonstrated that the association of HL with $\mathrm{d} 72$ was considerably lower in the 427 children (21\%) with high admitting BUN (OR 2.33; 95\% CI 1.11, 4.89; $p=0.025)$ and much higher in the 655 children (22\%) with crackles on auscultation (OR 29.45; 95\% CI 10.13, 85.55; $p<0.001$ ) (Additional file 1).

\section{Lactate clearance at $8 \mathrm{~h}$ and mortality}

Of all children included in the analysis, 2748/3008 (91.4\%) were alive and had a blood lactate level measured at $8 \mathrm{~h}$ of randomisation; 1906 (63.3\%) of these had an elevated lactate level $(\geq 2.5 \mathrm{mmol} / \mathrm{L})$ on admission and contributed to the LC analysis. Table 3 summarises the absolute and relative $\mathrm{LC}$ and lactate normalisation parameters at $8 \mathrm{~h}$ by primary outcome. Overall, the median lactate at $8 \mathrm{~h}$ was $3.4 \mathrm{mmol} / \mathrm{L}$ (IQR 2.3-5.1), the median absolute LC (change from baseline in lactate level) was $1.6 \mathrm{mmol} / \mathrm{L}$ (IQR 0.1-4.6), and the median relative LC (from baseline value) was 36\% (IQR 3.3$59 \%)$. Children who survived to $72 \mathrm{~h}$ had a lower median lactate $(3.3$ vs $5.4 \mathrm{mmol} / \mathrm{L}, p<0.001)$ and a higher 
Table 1 Clinical and laboratory characteristics on admission by in-hospital mortality at $72 \mathrm{~h}$

\begin{tabular}{|c|c|c|c|c|c|}
\hline & Survivors & Non-survivors & Total & Unadjusted OR of death $(95 \% \mathrm{Cl})$ & $p$ value \\
\hline Number, N (\%) & $2699(90)$ & $309(10)$ & 3008 & - & - \\
\hline \multicolumn{6}{|l|}{ General } \\
\hline Female & $1240 / 2699(46)$ & $147 / 309(5)$ & $1387 / 3008(46)$ & $1.07(0.84,1.35)$ & 0.59 \\
\hline Age (months); median (IQR) ${ }^{c}$ & $24(14,39)$ & $23(11,38)$ & $24(13,38.5)$ & - & $0.77^{d}$ \\
\hline Age $<12$ months & 494/2699 (16) & $83 / 309$ (3) & $577 / 3008(19)$ & $1.64(1.25,2.15)$ & $<0.001$ \\
\hline Middle-arm circumference $\leq 11.5 \mathrm{~cm}$ & $56 / 2644(1.95)$ & $13 / 199(0.5)$ & $69 / 2843(2.4)$ & $3.23(1.73,6)$ & $<0.001$ \\
\hline Axillary temperature $>39^{\circ} \mathrm{C}$ & 658/2694 (22) & $45 / 309(1)$ & 703/3003 (23) & $0.62(0.44,0.86)$ & $<0.01$ \\
\hline Hypothermia (temperature $<36{ }^{\circ} \mathrm{C}$ ) & 133/2694 (4) & $53 / 309(2)$ & 186/3003 (6) & $3.99(2.82,5.64)$ & $<0.001$ \\
\hline \multicolumn{6}{|l|}{ Respiratory } \\
\hline Respiratory rate; median $(\mathrm{IQR})^{\mathrm{c}}$ & $57(48,67)$ & $60(50,70)$ & $57(48,67)$ & - & $0.03^{d}$ \\
\hline Respiratory distress & 2183/2688 (73) & 280/308 (9) & 2463/2996 (82) & $2.31(1.55,3.46)$ & $<0.001$ \\
\hline Deep breathing & $1674 / 2697(56)$ & 261/308 (8) & 1935/3005 (64) & $2.47(1.95,3.14)$ & $<0.001$ \\
\hline Hypoxaemia (oxygen saturation $\leq 90 \%$ ) & $521 / 2626(18)$ & $113 / 271(4)$ & 634/2897 (22) & $2.89(2.22,3.76)$ & $<0.001$ \\
\hline Crackles on auscultation & $543 / 2697(18)$ & $112 / 308(4)$ & 655/3005 (22) & $2.27(1.76,2.92)$ & $<0.001$ \\
\hline \multicolumn{6}{|l|}{ Cardiovascular } \\
\hline Severe tachycardia ${ }^{\text {e }}$ & $1955 / 2697(73)$ & 165/308 (54) & 2120/3005 (71) & $0.44(0.34,0.56)$ & $<0.001$ \\
\hline Bradycardia & 15/2698 (0.6) & 2/3071 (7) & 36/3005 (1.2) & $13.13(6.62,26)$ & $<0.001$ \\
\hline \multicolumn{6}{|l|}{ Capillary refill time: } \\
\hline$<2 s$ & $921 / 2696(34)$ & $53 / 308(17)$ & 974/3004 (32) & $1.00{\text { (Ref. })^{f}}^{\prime}$ & \\
\hline $2-3 s$ & $1130 / 2696(42)$ & 109/308 (35) & $1239 / 3004(41)$ & $2.50(1.83,3.40)$ & $<0.001$ \\
\hline$\geq 3 \mathrm{~s}$ & $645 / 2696(24)$ & $146 / 308(47)$ & 791/3004 (26) & $2.87(2.25,3.66)$ & $<0.001$ \\
\hline Lower limb temperature gradient ${ }^{9}$ & $1544 / 2699(57)$ & 233/309 (75) & 1777/3008 (59) & $2.29(1.75,3.01)$ & $<0.001$ \\
\hline Weak radial pulse & 486/2699 (18) & 149/309 (48) & 635/3008 (21) & $4.24(3.30,5.45)$ & $<0.001$ \\
\hline Moderate hypotension ${ }^{\text {h }}$ & 162/2664 (6) & 40/289 (14) & 202/2953 (7) & $2.48(1.71,3.60)$ & $<0.001$ \\
\hline Dehydration (sunken eyes or reduced skin turgor) & $178 / 2697(7)$ & $51 / 307(17)$ & 229/3004 (8) & $2.82(2.01,3.96)$ & $<0.001$ \\
\hline \multicolumn{6}{|l|}{ Neurological } \\
\hline \multicolumn{6}{|l|}{ Level of consciousness: } \\
\hline Alert & $657 / 2696(24)$ & 22/309 (7) & $679 / 3005(23)$ & 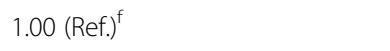 & \\
\hline Prostrate ${ }^{i}$ & $1714 / 2696(64)$ & $171 / 309(55)$ & $1885 / 3005(63)$ & $2.98(1.89,4.69)$ & $<0.001$ \\
\hline Coma $^{j}$ & $325 / 2696(12)$ & 116/309 (38) & $441 / 3005(15)$ & $10.66(6.63,17.14)$ & $<0.001$ \\
\hline Convulsions in this illness & $301 / 2698(11)$ & $48 / 309(16)$ & $349 / 3007(12)$ & $1.40(1.00,1.95)$ & 0.05 \\
\hline \multicolumn{6}{|l|}{ Clinical anaemia } \\
\hline Severe pallork & $969 / 2694(36)$ & $170 / 309(55)$ & 1139/3003 (38) & $2.18(1.71,2.77)$ & $<0.001$ \\
\hline Haemoglobinuria (history of dark urine) & $339 / 2694(1.4)$ & 40/307 (13) & $379 / 3001(13)$ & $1.21(0.95,1.54)$ & 0.13 \\
\hline Jaundice & $833 / 2695(31)$ & $133 / 309(43)$ & 966/3004 (32) & $1.65(1.30,2.10)$ & $<0.001$ \\
\hline \multicolumn{6}{|l|}{ Laboratory tests } \\
\hline Lactate $(\mathrm{mmol} / \mathrm{L}) ;$ median $(\mathrm{IQR})^{c}$ & $3.4(2.2,6.9)$ & $10.9(5.2,13.6)$ & $3.8(2.3,8)$ & - & $<0.001^{\circ}$ \\
\hline \multicolumn{6}{|l|}{ Hyperlactataemia (lactate, mmol/L) } \\
\hline No $(<2.5)$ & $856 / 2699(32)$ & 25/309 (8) & $881 / 3008(29)$ & $1.00{\text { (Ref. })^{f}}^{f}$ & \\
\hline Moderate (2.5-5) & 902/2699 (33) & 46/309 (15) & 948/3008 (32) & $1.75(1.06,2.87)$ & 0.03 \\
\hline Severe $(\geq 5)$ & $941 / 2699(35)$ & 238/309 (77) & $1179 / 3008(39)$ & $8.66(5.6,13.4)$ & $<0.001$ \\
\hline \multicolumn{6}{|l|}{ Severe acidaemia: } \\
\hline $\mathrm{pH}<7.2$ & 138/1816 (8) & 70/208 (34) & 208/2024 (10) & $6.17(4.35,8.74)$ & $<0.001$ \\
\hline Base deficit $>-8 \mathrm{mmol} / \mathrm{L}$ & $869 / 1809$ (48) & 170/203 (84) & 1039/2012 (58) & $5.57(3.76,8.26)$ & $<0.001$ \\
\hline
\end{tabular}


Table 1 Clinical and laboratory characteristics on admission by in-hospital mortality at 72 h (Continued)

\begin{tabular}{|c|c|c|c|c|c|}
\hline & Survivors & Non-survivors & Total & Unadjusted OR of death $(95 \% \mathrm{Cl})$ & $p$ value $^{a}$ \\
\hline Bicarbonate $<15 \mathrm{mmol} / \mathrm{L}$ & $588 / 1808$ (3) & $151 / 206(73)$ & 739/2014(37) & $5.69(4.07,7.97)$ & $<0.001$ \\
\hline Haemoglobin (g/dL): & & & 2930 & & \\
\hline$\geq 10$ & $648 / 2628(25)$ & $42 / 302(14)$ & 690/2930 (24) & $1.00{\text { (Ref. })^{f}}^{\prime}$ & \\
\hline 7 to $<10$ & $720 / 2628(27)$ & $80 / 302(27)$ & $800 / 2930(27)$ & $1.71(1.16,2.53)$ & $<0.01$ \\
\hline 5 to $<7$ & $437 / 2628(17)$ & 45/302 (15) & 482/2930 (16) & $1.59(1.02,2.46)$ & 0.04 \\
\hline$<5$ & $823 / 2628(31)$ & 135/302 (45) & 958/2930 (33) & $2.53(1.76,3.64)$ & $<0.001$ \\
\hline Glucose $(\mathrm{mmol} / \mathrm{L})$; median $(\mathrm{IQR})^{c}$ & $6.9(5.5,8.70)$ & $5.95(3.6,9.1)$ & $6.9(5.4,8.7)$ & - & $<0.001^{d}$ \\
\hline Hypoglycaemia (glucose < $2.5 \mathrm{mmol} / \mathrm{L}$ ) & $82 / 2615(3)$ & $48 / 300(16)$ & 130/915 (4) & $5.88(4.00,8.66)$ & $<0.001$ \\
\hline Blood urea nitrogen $(\mathrm{BUN}) \geq 7.14 \mathrm{mmol} / \mathrm{L}$ & 337/1819 (19) & $90 / 205(44)$ & $427 / 2024(21)$ & $3.44(2.54,4.67)$ & $<0.001$ \\
\hline Hyperkalaemia ( $\geq 6$ mmol/L) & 50/1768 (3) & $37 / 197(19)$ & 87/1965 (4) & $7.90(4.98,12.7)$ & $<0.001$ \\
\hline \multicolumn{6}{|l|}{ Microbiology } \\
\hline Malaria parasitaemia, positive' & $1571 / 2695(58)$ & 148/307 (48) & $1719 / 3002(57)$ & $0.67(0.53,0.84)$ & $<0.001$ \\
\hline HIV antibody, positive & $86 / 2197(4)$ & $20 / 220(9)$ & 106/2417(4) & $2.46(1.48,4.08)$ & $<0.001$ \\
\hline Blood culture, positive & 106/947 (11) & $17 / 105(16)$ & $123 / 1052$ (12) & $1.53(0.88,2.68)$ & 0.13 \\
\hline
\end{tabular}

${ }^{a}$ Chi-squared test $p$ values

${ }^{b}$ Of 3170 children enrolled in the FEAST trial, 162 did not have lactate measured at baseline

CIQR: percentile 25 , percentile 75

'Wilcoxon rank sum test $p$ value

e Severe tachycardia was defined as $>180$ beats per minute (bpm) in children $<12$ months, $>160$ bpm in children aged 12 months to 5 years, and $>140$ bpm for those aged $>5$ years

fRef: Reference group

${ }^{9}$ Temperature gradient was assessed by running the back of the hand from the toe to the knee; a positive temperature gradient was defined as a notable temperature change from cold (dorsum of foot) to warm (knee)

${ }^{\mathrm{h}}$ Moderate hypotension was defined as systolic blood pressure of $50-75 \mathrm{mmHg}$ in children younger than $12 \mathrm{months}, 60-75 \mathrm{mmHg}$ in those $12 \mathrm{months}$ to years, and $70-85 \mathrm{mmHg}$ in those older than 5 years, as measured by automated blood pressure monitor

'Prostration was defined as the inability of a child older than 8 months of age to sit upright or the inability of a child 8 months of age or younger to breast feed jComa was defined as the inability to localise a painful stimulus

kPallor manifested in lips, gums, or inner eyelids

'Positive on quality-controlled malaria slide, or, if missing, on rapid diagnostic test

relative $\mathrm{LC}(37 \%$ vs $17 \%, p<0.01)$ at $8 \mathrm{~h}$. Median relative LC was significantly higher in children with severe HL (54\%; IQR 28-70) than in those with moderate HL (15\%; IQR -19 to 38$)(p<0.001)$. Children with malaria had a similar relative LC as those with other severe febrile illnesses (37\% vs $35 \%, p=0.4)$.

At $8 \mathrm{~h}, 566$ children (30\%) had a relative $\mathrm{LC}<10 \%$, whereas a total of $1014(53 \%)$ met the pre-defined LC criteria (LC decline $\geq 40 \%$ [878, 46\%] and/or lactate normalisation $[<2.5 \mathrm{mmol} / \mathrm{L}][554,29 \%])$. After full adjustment for confounders, including the effects of lactate level on admission and the FEAST trial (fluid) intervention arm, failure to clear lactate $(\mathrm{LC}<10 \%)$ at $8 \mathrm{~h}$ of treatment was strongly associated with death at $72 \mathrm{~h}$ (OR 4.62; 95\% CI 2.7, 8; $p<0.001$ ). Furthermore, achieving the combined LC pre-defined goal was the strongest prognostic factor of survival (OR 0.24; 95\% CI 0.14, 0.42; $p<0.001)$ compared to relative LC or lactate normalisation alone (Table 4).

Persistent severe $\mathrm{HL}$ at $8 \mathrm{~h}$ remained a strong independent risk factor of death at $72 \mathrm{~h}$ (OR 4.60; 95\% CI $2.61-8.1 ; p<0.001)$. Of note, as previously demonstrated in the FEAST trial, fluid boluses were strongly associated with death at $72 \mathrm{~h}$ (OR 2.48; 95\% CI 1.36,
4.51; $p<0.01)$ in the full-adjusted logistic regression model.

\section{ROC analysis and lactate cut-offs}

The area under the receiver operator curve (AUROC) for $\mathrm{d} 72$ based on lactate at admission was 0.77 (95\% CI $0.74-0.80$ ), with no statistically significant difference in AUROC amongst children with and without malaria ( $p$ $=0.47$ ) (Fig. 1). The AUROC based on lactate at $8 \mathrm{~h}$ was 0.73 (95\% CI 0.68-0.77), with again no difference by malaria status $(p=0.55)$. The overall AUROC based on $\mathrm{LC}$ at $8 \mathrm{~h}$ was 0.58 (95\% CI 0.53-0.64), and for the group of children with severe HL $(>5 \mathrm{mmol} / \mathrm{L}$ ) on admission it was greater $(0.68 ; 95 \%$ CI $0.62-0.75)$. Lastly, the AUROC for $\mathrm{d} 72$ based on a logistic regression model for LC at $8 \mathrm{~h}$ was even more predictive as 0.84 (95\% CI 0.80-0.88) (Fig. 2).

Sensitivity and specificity analysis identified that for children without falciparum malaria a lactate level on admission of $\geq 3.4 \mathrm{mmol} / \mathrm{L}$ had a sensitivity to predict mortality at $72 \mathrm{~h}$ of $80 \%$ and a specificity of $61.6 \%$, whereas for children with malaria a sensitivity of $80 \%$ corresponded with a lactate cut-off value of $5.2 \mathrm{mmol} / \mathrm{L}$ (specificity of 59.2\%). For a baseline lactate level of $\geq 5$ 
Table 2 Multivariate analysis (logistic regression model) of clinical and laboratory factors at admission associated with mortality at $72 \mathrm{~h}$ of randomisation

\begin{tabular}{|c|c|c|c|}
\hline & Categories & Adjusted OR of death $(95 \% \mathrm{Cl})$ & $p$ value $^{\mathrm{a}}$ \\
\hline \multirow[t]{2}{*}{ Age (months) } & $\geq 12$ & $1.00{\text { (Ref. })^{b}}^{b}$ & $<0.01$ \\
\hline & $<12$ & $1.98(1.22,3.2)$ & \\
\hline \multirow[t]{2}{*}{ Gender } & Male & $1.00{\text { (Ref. })^{b}}^{b}$ & 0.96 \\
\hline & Female & $1.01(0.71,1.46)$ & \\
\hline \multirow[t]{6}{*}{ Site } & Mbale & 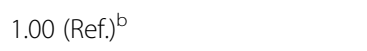 & \\
\hline & Kilifi & $1.56(0.76,3.23)$ & 0.23 \\
\hline & Mulago & $1.47(0.80,2.70)$ & 0.21 \\
\hline & Soroti & $1.16(0.64,2.14)$ & 0.63 \\
\hline & Lacor & - & - \\
\hline & Teule & $2.04(0.87,4.76)$ & 0.10 \\
\hline \multirow[t]{3}{*}{ Lactate stratum (mmol/L) } & No $(<2.5)$ & 1.00 (Ref.) $^{b}$ & \\
\hline & Moderate (2.5-5) & $1.28(0.62,2.63)$ & 0.50 \\
\hline & Severe $(\geq 5)$ & $6.96(3.52,13.76)$ & $<0.001$ \\
\hline \multirow[t]{3}{*}{ Level of consciousness } & Alert & 1.00 (Ref. $^{b}$ & \\
\hline & Prostration & $1.41(0.72,2.76)$ & 0.31 \\
\hline & Coma & $6.87(3.36,14.04)$ & $<0.001$ \\
\hline \multirow[t]{2}{*}{ BUN $(m m o l / L)^{d}$} & $<7.14$ & $1.00{\text { (Ref. })^{b}}^{b}$ & $<0.001$ \\
\hline & $\geq 7.14$ & $2.92(1.84,4.62)$ & \\
\hline \multirow[t]{2}{*}{ Malaria } & No & 1.00 (Ref. $^{b}$ & $<0.001$ \\
\hline & Yes & $0.45(0.29,0.69)$ & \\
\hline \multirow[t]{2}{*}{ Severe anaemia $(\mathrm{Hb}<5 \mathrm{~g} / \mathrm{dL})$} & No & 1.00 (Ref. $)^{b}$ & 0.37 \\
\hline & Yes & $0.81(0.50,1.29)$ & \\
\hline \multirow[t]{2}{*}{ Hyperglycaemia $^{c}$ (glucose $\geq 8.3 \mathrm{mmol} / \mathrm{L}$ ) } & No & 1.00 (Ref.) $)^{2}$ & 0.55 \\
\hline & Yes & $0.84(0.55,1.30)$ & \\
\hline \multirow[t]{2}{*}{ HIV } & No & $1.00(\text { Ref. })^{2}$ & 0.05 \\
\hline & Yes & $2.16(1.01,4.60)$ & \\
\hline
\end{tabular}

Wald test $p$ values

${ }^{\mathrm{b}}$ Ref: Reference group

${ }^{\mathrm{C}}$ Moderate evidence of interaction, stratum-specific odds ratios are shown in Additional file 1

${ }^{\mathrm{d} B l o o d}$ Urea Nitrogen

$\mathrm{mmol} / \mathrm{L}$, the sensitivity in children without malaria was $71.7 \%$ (specificity $75.53 \%$ ), whereas in those with malaria it was $82.43 \%$ (specificity $57.7 \%$ ). This indicates that in non-malaria cases, lower levels of HL have a similar effect on 72-h mortality.

\section{Discussion}

Our study confirms the association between HL on hospital admission and mortality, and it demonstrates that a failure to clear lactate (relative $\mathrm{LC}<10 \%$ ) within the first $8 \mathrm{~h}$ of treatment is a relevant prognostic factor of early death in severely ill febrile children in a malaria-endemic area irrespective of the underlying diagnosis (malaria, sepsis, or other severe febrile illness). Importantly, this is the first paediatric study to demonstrate that a relative LC $\geq 40 \%$ and/or lactate normalisation within the first 8 $\mathrm{h}$ of treatment strongly predicts 72 -h survival in this context.

These results, derived from a very large multicentre randomised trial, are compelling and raise the question of whether LC could be a simple, valid and cost-effective riskstratification tool, as well as a potential therapeutic target to guide resuscitation in children with severe febrile illnesses in resource-poor settings. Furthermore, it is not limited to children with specific diagnoses, but rather covers different presentation syndromes, which reflects the population of children presenting to hospital in the setting in which the trial was conducted. Lastly, for research studies the inclusion of lactate level could be used for inter-site or intercentre comparisons of disease severity.

Despite a paucity of paediatric data, our findings are supported by the literature. A recent meta-analysis [25] 
Table 3 Lactate clearances within first $8 \mathrm{~h}$ of randomisation in survivors and non-survivors at $72 \mathrm{~h}$

\begin{tabular}{|c|c|c|c|c|c|}
\hline & Survivors & Non-survivors & Total & Unadjusted OR of death $(95 \% \mathrm{Cl})$ & $p$ value \\
\hline \multicolumn{6}{|c|}{ Lactate clearance at $8 \mathrm{~h}$ amongst children with an abnormal lactate on admission $\geq 2.5 \mathrm{mmol} / \mathrm{L}^{\mathrm{b}}$} \\
\hline Number, N (\%) & $1792(94)$ & $114(6)$ & 1906 & - & - \\
\hline Lactate at $8 \mathrm{~h}(\mathrm{mmol} / \mathrm{L})$; median $(\mathrm{IQR})^{\mathrm{c}}$ & $3.3(2.3,5)$ & $5.4(3.4,10)$ & $3.4(2.3,5.1)$ & - & $<0.001^{\mathrm{d}}$ \\
\hline Absolute LC (mmol/L); median (IQR) ${ }^{c}$ & $1.7(0.2,4.5)$ & $1.3(-0.5,4.7)$ & $1.6(0.1,4.6)$ & - & $0.12^{\mathrm{d}}$ \\
\hline Relative LC (\%); median (IQR) ${ }^{c}$ & $37(3.7,59.5)$ & $17(-6,51)$ & $36(3.33,59)$ & - & $0.003^{d}$ \\
\hline Relative LC < 10\% & $516 / 1792(29)$ & $50 / 114(44)$ & $566 / 1906(30)$ & $1.93(1.31,2.84)$ & $<0.001$ \\
\hline Relative LC $\geq 40 \%$ & $840 / 1792(47)$ & 38/114 (33) & 878/1906 (46) & $0.57(0.38,0.85)$ & $<0.01$ \\
\hline Lactate normalisation $^{\mathrm{e}}$ & $540 / 1792(30)$ & 14/114 (12) & $554 / 1906(29)$ & $0.33(0.18,0.57)$ & $<0.001$ \\
\hline Relative LC $\geq 40 \%$ and/or lactate normalisation & 973/1792 (54) & $41 / 114(36)$ & 1014/1906 (53) & $0.47(0.32,0.70)$ & $<0.001$ \\
\hline \multicolumn{6}{|c|}{ Lactate clearance at $8 \mathrm{~h}$ amongst those with lactate on admission $\geq 5 \mathrm{mmol} / \mathrm{L}^{\mathrm{f}}$} \\
\hline N (\%) & 919 (92) & $85(8)$ & 1004 & - & - \\
\hline Lactate at $8 \mathrm{~h}$; median $(\mathrm{IQR})^{\mathrm{c}}$ & $3.9(2.7,6)$ & $6.8(4.1,11.3)$ & $4.1(2.8,6.3)$ & - & $<0.001^{\mathrm{d}}$ \\
\hline Absolute LC (mmol/L); median (IQR) ${ }^{c}$ & $4.4(2.4,7.7)$ & $2.3(0,5.8)$ & $4.3(2.3,7.6)$ & - & $<0.001^{\mathrm{d}}$ \\
\hline Relative LC (\%); median (IQR) & $55(32,71)$ & $23(0,62)$ & $54(28,70)$ & - & $<0.001^{\mathrm{d}}$ \\
\hline Relative LC < 10\% & $116 / 919(13)$ & $33 / 85(39)$ & 149/1004 (15) & $4.40(2.70,7.16)$ & $<0.001$ \\
\hline Relative LC $\geq 40 \%$ & $628 / 919(68)$ & $33 / 85(39)$ & $661 / 1004(66)$ & $0.29(0.18,0.47)$ & $<0.001$ \\
\hline Lactate normalisation $^{e}$ & 200/919 (22) & $6 / 85(7)$ & 206/1004 (21) & $0.27(0.12,0.64)$ & 0.001 \\
\hline Relative LC $\geq 40 \%$ and/or lactate normalisation & 628/919 (68) & 33/85 (39) & 661/1004 (66) & $0.29(0.18,0.47)$ & $<0.001$ \\
\hline
\end{tabular}

${ }^{\mathrm{a}}$ Chi-squared test $p$ values

${ }^{\mathrm{b}}$ Total of 811 children with normal lactate levels on admission $(<2.5 \mathrm{mmol} / \mathrm{L})$ excluded

'Ref: Reference group

Wilcoxon rank-sum test $p$ values

e Lactate decline $<2.5 \mathrm{mmol} / \mathrm{L}$ in the first $8 \mathrm{~h}$ after randomisation

f 1713 children with lactate levels on admission $<5 \mathrm{mmol} / \mathrm{L}$ excluded

and a large systematic review [17] of acutely ill adults have reported a consistent lower mortality associated with LC, not limited to septic patients and regardless of the initial lactate value. Also, a recent secondary analysis of two large clinical trials on antimalarials has shown that lack of LC is an independent predictor of death in adults with severe malaria [26]. Amongst the few paediatric studies published, Krishna and colleagues measured serial lactate concentrations during $24 \mathrm{~h}$ in a small cohort of 115 children with severe malaria in the Gambia, concluding that sustained HL was the most powerful prognostic indicator of fatal outcome [21]. In another cohort of 65 children admitted to a paediatric intensive care unit (PICU) with septic shock in South Korea, Kim et al. [22] found that the area under the curve (AUC) of serial lactates measured during the first $24 \mathrm{~h}$ had a strong predictive power of mortality at 28 days (ROC AUC 0.828). Munde et al. [27] recently reported that a relative LC $<30 \%$ at $6 \mathrm{~h}$ predicted mortality in PICU children in India comparably to the more complex Paediatric Risk of Mortality (PRISM) score, standard in paediatric intensive care.

It is therefore possible that failure to clear lactate within the first hours of therapy could serve as a simpler risk stratification tool in malaria-endemic areas, potentially more reliable than absolute lactate values alone and easier to apply than more complex clinical scores. However, to have an outcome benefit, a similar lack of LC effect should likely be shown at an interval shorter than $8 \mathrm{~h}$ that would allow a therapeutic intervention or the appropriate recruitment into clinical trials of those children with a higher chance to die.

Moreover, to demonstrate an association between LC and survival in severely ill febrile children in a malariaendemic area is relevant at least in two aspects. On one hand, LC could serve as a valid surrogate endpoint of clinical trials of malaria aiming to improve mortality, as recently demonstrated by Jeeyapant et al. in a large cohort of adult patients with malaria [26]. Thus, one could hypothesise that LC might help to guide the initial resuscitation of these children in a resource-poor setting, where invasive monitoring and intensive care is mostly unavailable. To date two multicentre randomised trials have assessed the clinical value of resuscitation strategies that included LC as a target in adults admitted to intensive care units, showing that quantitative resuscitation based on LC was non-inferior or even superior to that based on $S_{\mathrm{cv}} \mathrm{O}_{2}$ alone $[18,19]$, and the most recent Surviving Sepsis Campaign guidelines suggest targeting resuscitation to lactate normalisation in adult septic 
Table 4 Multivariable analysis of clinical and laboratory factors associated with death at $72 \mathrm{~h}$ including LC at $8 \mathrm{~h}$ post-randomisation

\begin{tabular}{|c|c|c|c|}
\hline & Categories & Adjusted OR of death $(95 \% \mathrm{Cl})$ & $p$ value \\
\hline \multirow[t]{2}{*}{ LC criteria $^{\mathrm{b}}$ at $8 \mathrm{~h}$} & No & $1.00(\text { Ref.) })^{c}$ & \multirow[t]{2}{*}{$<0.001$} \\
\hline & Yes & $0.24(0.14,0.42)$ & \\
\hline \multirow[t]{2}{*}{ Hyperlactataemia on admission ( $\geq 5 \mathrm{mmol} / \mathrm{L}$ ) } & No & $1.00(\text { Ref. })^{c}$ & \multirow[t]{2}{*}{$<0.001$} \\
\hline & Yes & $6.61(3.56,12.30)$ & \\
\hline \multirow[t]{2}{*}{ FEAST fluid intervention arm } & Control & $1.00(\text { Ref. })^{c}$ & \multirow[t]{2}{*}{$<0.01$} \\
\hline & Fluid bolus & $2.48(1.36,4.51)$ & \\
\hline \multirow[t]{2}{*}{ Malaria } & No & 1.00 (Ref.) $^{c}$ & \multirow[t]{2}{*}{0.01} \\
\hline & Yes & $0.52(0.31,0.87)$ & \\
\hline \multirow[t]{2}{*}{ Severe anaemia } & No & 1.00 (Ref.) $)^{c}$ & \multirow[t]{2}{*}{0.05} \\
\hline & Yes & $0.57(0.32,0.99)$ & \\
\hline \multirow[t]{3}{*}{ Level of consciousness } & Alert & 1.00 (Ref.) $)^{c}$ & \\
\hline & Prostration & $0.87(0.38,2)$ & 0.78 \\
\hline & Coma & $4.29(1.8,10.24)$ & 0.001 \\
\hline \multirow[t]{2}{*}{ BUN (mmol/L) } & $<7.14$ & $1.00(\text { Ref. })^{c}$ & \multirow[t]{2}{*}{$<0.001$} \\
\hline & $\geq 7.14$ & $3.13(1.80,5.43)$ & \\
\hline \multirow[t]{2}{*}{ Age (months) } & $\geq 12$ & $1.00(\text { Ref. })^{c}$ & \multirow[t]{2}{*}{$<0.001$} \\
\hline & $<12$ & $3.37(1.95,5.82)$ & \\
\hline \multirow[t]{2}{*}{ Gender } & Male & $1.00(\text { Ref. })^{c}$ & \multirow[t]{2}{*}{0.66} \\
\hline & Female & $1.11(0.69,1.81)$ & \\
\hline \multirow[t]{6}{*}{ Site } & Mbale & 1.00 (Ref.) $^{c}$ & \\
\hline & Kilifi & $2.16(0.82,5.75)$ & 0.12 \\
\hline & Mulago & $2.73(1.29,5.78)$ & $<0.01$ \\
\hline & Soroti & $1.31(0.58,2.95)$ & 0.52 \\
\hline & Lacor & $3.12(1.19,8.2)$ & 0.02 \\
\hline & Teule & $2.93(1.05,8.22)$ & 0.04 \\
\hline
\end{tabular}

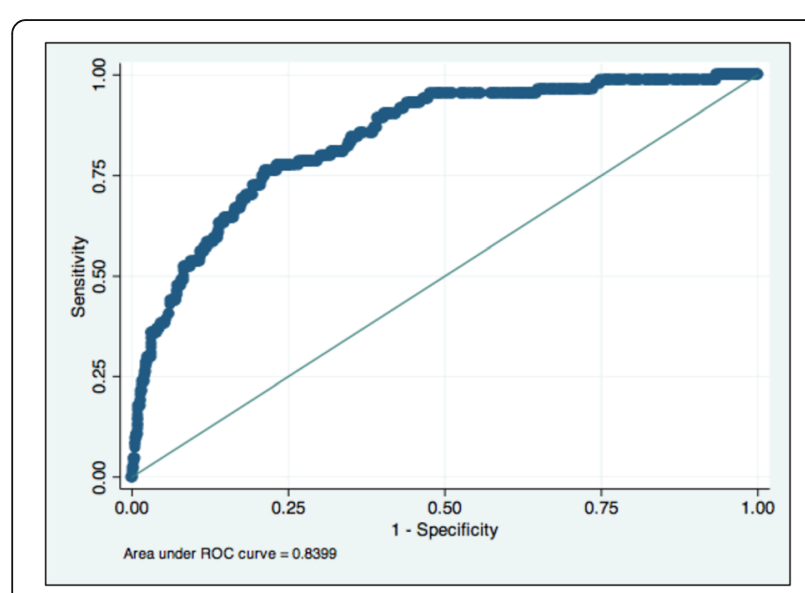

Fig. 2 ROC curve for mortality at $72 \mathrm{~h}$ of randomisation based on logistic regression model for lactate clearance (LC) at $8 \mathrm{~h}$. LC was defined as a relative $L C \geq 40 \%$ and/or lactate normalisation (lactate $<2.5 \mathrm{mmol} / \mathrm{L}$ ) within the first $8 \mathrm{~h}$ of treatment patients with HL, although accept a weak evidence exists for this recommendation [28].

Unfortunately, the observational design of our study does not allow one to answer whether targeting resuscitation to achieve a specific relative LC or lactate normalisation improves outcomes in severely ill febrile children in this context. Interestingly, a recent study including 218 adult patients with severe infection at a regional referral hospital in Uganda [29] questioned whether serial assessment of vital signs combined with point-of-care lactate at $6 \mathrm{~h}$ could be a feasible method of monitoring patients being resuscitated from severe sepsis or malaria in a resource-poor setting. Despite an improvement in vital signs and lactate values at $6 \mathrm{~h}$ of resuscitation, the authors could not demonstrate an association between an LC $\geq 10 \%$ and improved in-hospital mortality. This study, however, was observational with a limited sample size where more than half of the participants had 
advanced HIV infection, it did not use a pre-defined treatment algorithm to target $\mathrm{LC}$, and it did not report adjusted OR for the association of interest.

Some other limitations of our study should be taken into account. First, despite the optimal LC threshold or the LC rate not having been clearly defined, many studies on LC in sepsis have used a relative clearance rate of $10-20 \%$ in repeated samples measured at 2- to 3-h intervals during the first $6 \mathrm{~h}$ of resuscitation. Our definition of LC criteria was based on published data $[14,18,19]$, the median $\mathrm{LC}$ value in our cohort, and the 8-h interval between lactate samples. A more extreme or loose definition could have yielded slightly different results. Moreover, the fact that LC in the FEAST trial was calculated at $8 \mathrm{~h}$ after randomisation for all participants prevents one from determining the precise moment when lactate normalisation or LC occurred for each individual. If some of the participants cleared their lactate significantly earlier than $8 \mathrm{~h}$ and that was associated with a better outcome, the true effect of lactate normalisation/LC on survival could be underestimated. However, 169/341 children (49.6\%) died before $8 \mathrm{~h}$, which again could have resulted in a relevant underestimation of the study results. The key point is that we chose the 8-h correction as this could be compared to other studies [26-28]; given the high proportion of mortality that occurred before this time point, an early assessment of LC may be more relevant to this setting to identify high-risk patient and initial resuscitation (either at 2 or $4 \mathrm{~h}$ ). Lastly, LC can be potentially useful when baseline HL exists, which was not the case for one third of our participants.

Whilst lactate levels can falsely increase with haemolysis, frequent with difficult phlebotomies or with long time span from extraction to processing, blood samples in the FEAST trial were obtained from a free-flowing vein and immediately measured at the bedside. Arterial lactates are recommended over peripheral venous lactates in sepsis studies looking at absolute values and clearance rate, due to poor agreement between both parameters [30]. Nevertheless, there are technical and ethical challenges in obtaining arterial samples in unsedated children, and the strong prognostic correlation with high admission venous lactate and LC with survival outcomes suggests that pragmatically venous samples should be suitable for critically sick children in resourcelimited hospitals. Lastly, lactate levels may increase with hyperglycaemia, unrelated to a tissue oxygen debt but related to a stress-induced increased glucose turnover. This so-called type B lactic acidosis usually resolves quickly after normalisation of glycaemia [31]. Only $6 \%$ of participants in the analysis had hyperglycaemia on admission, so it is unlikely this would have introduced a bias in the overall analysis. However, some evidence of an effect modification was found between $\mathrm{HL}$ and hyperglycaemia (see Additional file 1), with a weakened association between HL and death in the presence of hyperglycaemia.

Relevant to the FEAST Paediatric Emergency Triage (PET) clinical score [5], which includes the presence of crackles (lung crepitations) on auscultation as a predictive maker of death, we too found that lung crepitations in association with high lactate strongly predicts $72-\mathrm{h}$ mortality (OR 29.90; 95\% CI 11.43-78.14) in children with shock, which most likely indicates the aetiology was sepsis due to pneumonia. This observation may help refine definitions of severe pneumonia, which are broad and non-specific. Interestingly, in the PET score analysis hypoxaemia (pulse oximetry reading $<90 \%$ ) did not independently predict poor outcome [5]. In this analysis, hypoxaemia was found to be independently associated with death at $72 \mathrm{~h}(\mathrm{OR} 1.72, p=0.01)$; however, as it did not confound or modify the association between HL and $\mathrm{d} 72$, it was not included in the logistic regression model. Moreover, children septic with pneumonia (defined as crackles on auscultation and presence of hyperlactataemia) were more likely to suffer from hypoxaemia (OR = $2.58 ; p<0.0001)$. Owing to the poor specificity of signs for pneumonia, WHO promotes the use of pulse oximeters to direct children with signs of pneumonia for oxygen therapy. Yet, pulse oximetry remains poorly implemented [32]. One example, therefore, of the utility of the PET score and/or use of lactate screening at admission is using lung crepitations in the future to screen for clinical trials examining novel therapies specifically for pneumonia in those at high risk for poor outcome.

Lastly, our findings suggest that the predictive values of lactate on admission for mortality are lower in children without malaria $(3.4 \mathrm{mmol} / \mathrm{L})$ than for those with malaria $(5.2 \mathrm{mmol} / \mathrm{L})$. This is important, as a detailed pathogenesis of HL in septic shock and and in malaria is still imperfectly understood and may actually differ. Whereas in sepsis HL is mostly viewed as a result of anaerobic metabolism secondary to systemic hypoperfusion [33], HL in malaria is likely an even more complex phenomenon, involving additional factors like sequestration of parasitised erythrocytes in the microcirculation, acute severe haemolytic anaemia, seizure activity, and end-products of parasite metabolism [34-36]. We have previously described the relationship between baselines haemoglobin and lactate (Additional file 2). This likely diverse pathogenesis of $\mathrm{HL}$ in bacterial sepsis and malaria could have implied a different prognostic value for mortality that would explain the different definitions of HL used in studies of sepsis and malaria. Thus, while the current consensus cut-off value for sepsis is a lactate $>2 \mathrm{mmol} / \mathrm{L}$ [37], most studies on severe malaria, where $\mathrm{HL}$ is particularly frequent and profound, use a lactate cut-off of $>5 \mathrm{mmol} / \mathrm{L}$, following the WHO definition 
criteria [38]. Our study indicates that appropriate lactate cut-off values, lower for children without malaria, should be included in the design of therapeutic algorithms for early risk stratification of severely ill children admitted to hospital in malaria-endemic areas.

\section{Conclusions}

In conclusion, severe HL, defined as a venous lactate level $\geq 5 \mathrm{mmol} / \mathrm{L}$ on hospital admission, is a strong risk factor for death within the first $72 \mathrm{~h}$ in children with severe febrile illnesses in east Africa, independently of the underlying diagnosis. Failure to clear lactate (relative LC $\leq 10 \%$ ) within $8 \mathrm{~h}$ is also strongly prognostic of death, which could serve as a simple risk-stratification tool or a surrogate endpoint of mortality in clinical trials. Those children able to normalise or clear their lactate by at least $40 \%$ within $8 \mathrm{~h}$ have an improved chance of survival. An LC measured at an earlier time point may have yielded even more relevant results owing to the high mortality prior to $8 \mathrm{~h}$ that occurred in our cohort. Whether LC alone, or in combination with other clinical markers, can be used as a cost-effective therapeutic target to guide initial resuscitation and ultimately improve clinical outcomes of severely ill febrile children in malaria-endemic areas, where lack of basic patient monitoring and intensive therapies is standard, remains uncertain. Given severe infection is the most common cause of death in children under 5 years of age in these settings, and that early and aggressive initial resuscitation is key for survival, this question warrants further investigation. These data provide the rationale for a clinical trial of lactate clearance as an early therapeutic resuscitation goal in children with severe infection in malaria-endemic areas. We encourage the use of point-ofcare lactate testing whenever possible in limited-resource settings to identify high-risk patients.

\section{Additional files}

Additional file 1: Multivariable analysis (logistic regression model) of clinical and laboratory factors associated with death at $72 \mathrm{~h}$ : fully adjusted OR (including interaction parameter between $\mathrm{HL}$ and hyperglycaemia, blood urea nitrogen levels, and crackles on auscultation). (DOCX $106 \mathrm{~kb}$ )

Additional file 2: Plots of the relationship between haemoglobin and lactate and mortality estimated from the adjusted Cox regression model. Originally published in BMC Medicine 13:174 by George et al. [5]. (PNG 80 kb)

\section{Abbreviations}

d72: Mortality at $72 \mathrm{~h}$ of hospital admission; FEAST: Fluid Expansion as Supportive Therapy; Hb: Haemoglobin; HL: Hyperlactataemia; LC: Lactate clearance

\section{Acknowledgements}

We thank the FEAST trial management group, the investigators at all sites, and all members of the trial steering, monitoring and review committees. Particular thanks are due to the children and families who participated in the FEAST trial.

\section{Funding}

The FEAST trial was supported by a grant (G0801439) from the Medical Research Council (MRC), UK, provided through the (MRC) Department for International Development (DFID) concordat. DMG, AB, and ECG were supported by this grant.

Centres for Global Health Research, Imperial College Centre for Global Health Research, UK Wellcome Trust (100693/Z/12/Z:)

DMG, AB and ECG were supported by the MRC (G0801439).

\section{Availability of data and materials}

Permission was obtained and a data sharing agreement signed with the MRC Clinical Trials Unit, University College London, UK, the FEAST Trial Management group, and the chair of the Trial Steering Committee. The datasets used and/or analysed during the current study are available from the corresponding author on reasonable request.

\section{Authors' contributions}

AA developed the research question and methodology, conducted the literature search, analysed the data, and wrote the manuscript draft. KM and JT contributed to the design, analysis, and interpretation of data and revision of the manuscript. SK, POO, RO, CE, SA, RN, and GM led the data collection. $E C G, D M G$, and $A B$ provided the data and contributed to interpretation of data and revision of the manuscript. DMG and $A B$ contributed to interpretation of data. All authors read and approved the final manuscript.

\section{Ethics approval and consent to participate}

The ethics committees at Imperial College (London, UK), Makerere University (Kampala, Uganda), the Medical Research Institute (Kenya), and the National Medical Research Institute (Tanzania) approved the trial protocol. Informed, written consent was obtained from parents/guardians of the research participants prior to enrolment in the study.

\section{Competing interests}

The authors declare that they have no competing interests.

\section{Publisher's Note}

Springer Nature remains neutral with regard to jurisdictional claims in published maps and institutional affiliations.

\section{Author details}

${ }^{1}$ Royal Brompton \& Harefield NHS Foundation Trust, Sydney Street, London SW3 6NP, UK. ${ }^{2}$ London School of Hygiene and Tropical Medicine, 15-17, Tavistock Place WC1H 9SH, London WC1H 9SH, UK. ${ }^{3}$ Medical Research Council Clinical Trials Unit (MRC CTU) at UCL, 125 Aviation House, Kingsway, London WC2B 6NH, UK. ${ }^{4}$ Department of Paediatrics, Mulago Hospital, Makerere College of Health Sciences, PO Box 7072, Kampala, Uganda. ${ }^{5}$ Department of Paediatrics, Mbale Regional Referral Hospital, Pallisa Road, PO Box 291, Mbale, Uganda. ${ }^{6}$ Mbale Clinical Research Institute (MCRI), Plot 29-33 Pallisa Rd, PO Box 1966, Mbale, Uganda. ${ }^{7}$ Department of Paediatrics, Soroti Regional Referral Hospital, PO Box 289, Soroti, Uganda. ${ }^{8}$ Kilifi Clinical Trials Facility, KEMRI-Wellcome Trust Research Programme, PO Box 203, Nairobi, Kenya. ${ }^{9}$ St Mary's Hospital, Lacor, PO Box 180, Gulu, Uganda. ${ }^{10}$ Teule Hospital, PO Box 81, Muheza, Tanzania. ${ }^{11}$ Department of Paediatrics, Faculty of Medicine, Imperial College, W2 1PG, London, UK.

Received: 4 November 2017 Accepted: 26 January 2018 Published online: 09 March 2018

\section{References}

1. CHERG-WHO methods and data sources for child causes of death 20002013. Global Health Observatory data. http://www.who.int/gho/child_ health/mortality/causes/en. Accessed 1 Oct 2017.

2. Molyneux E. Paediatric emergency care in developing countries. Lancet. 2001;357:86-7.

3. Molyneux E, Ahmad S, Robertson A. Improved triage and emergency care for children reduces inpatient mortality in a resource-constrained setting. Bull World Health Organ. 2006;84:314-9.

4. World Health Organization. Pocket book of hospital care for children. 2nd edition. Guidelines for the management of common childhood illnesses. Geneva: World Health Oganization; 2013. 
5. George EC, Walker AS, Kiguli S, Olupot-Olupot P, Opoka RO, Engoru C, Akech SO, Nyeko R, Mtove G, Reyburn H, Berkley JA, Mpoya A, Levin M, Crawley J, Gibb DM, Maitland K, Babiker AG. Predicting mortality in sick African children: the FEAST Paediatric Emergency Triage (PET) Score. BMC Med. 2015;13:174.

6. Mikkelsen ME, Miltiades AN, Gaieski DF, Goyal M, Fuchs BD, Shah CV, Bellamy $\mathrm{SL}$, Christie JD. Serum lactate is associated with mortality in severe sepsis independent of organ failure and shock. Crit Care Med. 2009;37:1670-7.

7. Marsh K, Forster D, Waruiru C, Mwangi I, Winstanley M, Marsh V, Newton C, Winstanley P. Warn P, Peshu N, et al. Indicators of life-threatening malaria in African children. N Engl J Med. 1995;332:1399-404.

8. Hanson JP, Lam SW, Mohanty S, Alam S, Pattnaik R, Mahanta KC, Hasan MU, Charunwatthana P, Mishra SK, Day NP, White NJ, Dondorp AM. Fluid resuscitation of adults with severe falciparum malaria: effects on acid-base status, renal function, and extravascular lung water. Crit Care Med. 2013:41:972-81.

9. Standage SW, Wong HR. Biomarkers for pediatric sepsis and septic shock. Expert Rev Anti-Infect Ther. 2011;9:71-9.

10. Reed L, Carroll J, Cummings A, Markwell S, Wall J, Duong M. Serum lactate as a screening tool and predictor of outcome in pediatric patients presenting to the emergency department with suspected infection. Pediatr Emerg Care. 2013:29:787-91.

11. Singer M, Deutschman CS, Seymour CW, Shankar-Hari M, Annane D, Bauer M, Bellomo R, Bernard GR, Chiche JD, Coopersmith CM, Hotchkiss RS, Levy MM, Marshall JC, Martin GS, Opal SM, Rubenfeld GD, van der Poll T, Vincent $J$, Angus DC. The Third International Consensus Definitions for Sepsis and Septic Shock (Sepsis-3). JAMA. 2016;315:801-10.

12. Morin L, Ray S, Wilson C, Remy S, Benissa MR, Jansen NJ, Javouhey E, Peters MJ, Kneyber M, De Luca D, Nadel S, Schlapbach LJ, Maclaren G, Tissieres P. ESPNIC Refractory Septic Shock Definition Taskforce. Refractory septic shock in children: a European Society of Paediatric and Neonatal Intensive Care definition. Intensive Care Med. 2016;42:1948-57.

13. Newton CR, Valim C, Krishna S, Wypij D, Olola C, Agbenyega T, Taylor TE. The prognostic value of measures of acid/base balance in pediatric falciparum malaria, compared with other clinical and laboratory parameters. Clin Infect Dis. 2005;41:948-57.

14. Arnold RC, Shapiro NI, Jones AE, Schorr C, Pope J, Casner E, Parrillo JE, Dellinger RP, Trzeciak S. Multicenter study of early lactate clearance as a determinant of survival in patients with presumed sepsis. Shock. 2009;32:35-9.

15. Puskarich MA, Trzeciak S, Shapiro NI, Albers AB, Heffner AC, Kline JA, Jones AE. Whole blood lactate kinetics in patients undergoing quantitative resuscitation for severe sepsis and septic shock. Chest. 2013;143:1548-53.

16. Zhang Z, Xu X, Chen K. Lactate clearance as a useful biomarker for the prediction of all-cause mortality in critically ill patients: a systematic review study protocol. BMJ Open. 2014;4:e004752.

17. Vincent $J \mathrm{~L}$, Quintairos ESA, Couto $L \mathrm{Jr}$, Taccone FS. The value of blood lactate kinetics in critically ill patients: a systematic review. Crit Care. 2016;20:257.

18. Jones AE, Shapiro NI, Trzeciak S, Arnold RC, Claremont HA, Kline JA. Lactate clearance vs central venous oxygen saturation as goals of early sepsis therapy: a randomized clinical trial. JAMA. 2010;303:739-46.

19. Jansen TC, van Bommel J, Schoonderbeek FJ, Sleeswijk Visser SJ, van der Klooster JM, Lima AP, Willemsen SP, Bakker J. Early lactate-guided therapy in intensive care unit patients: a multicenter, open-label, randomized controlled trial. Am J Respir Crit Care Med. 2010;182:752-61.

20. Scott HF, Brou L, Deakyne SJ, Fairclough DL, Kempe A, Bajaj L. Lactate clearance and normalization and prolonged organ dysfunction in pediatric sepsis. J Pediatr. 2016;170:149-155.e4.

21. Krishna S, Waller DW, ter Kuile F, Kwiatkowski D, Crawley J, Craddock CF, Nosten F, Chapman D, Brewster D, Holloway PA, et al. Lactic acidosis and hypoglycaemia in children with severe malaria: pathophysiological and prognostic significance. Trans R Soc Trop Med Hyg. 1994;88:67-73.

22. Kim YA, Ha EJ, Jhang WK, Park SJ. Early blood lactate area as a prognostic marker in pediatric septic shock. Intensive Care Med. 2013;39:1818-23.

23. Maitland K, Kiguli S, Opoka RO, Engoru C, Olupot-Olupot P, Akech SO, Nyeko R, Mtove G, Reyburn H, Lang T, Brent B, Evans JA, Tibenderana JK, Crawley J, Russell EC, Levin M, Babiker AG, Gibb DM. Mortality after fluid bolus in African children with severe infection. N Engl J Med. 2011;364: 2483-95.

24. Kiguli S, Maitland K, George EC, Olupot-Olupot P, Opoka RO, Engoru C, Akech SO, Nyeko R, Mtove G, Reyburn H, Levin M, Babiker AG, Gibb DM, Crawley J. Anaemia and blood transfusion in African children presenting to hospital with severe febrile illness. BMC Med. 2015;13:21.
25. Zhang $Z, X u X$. Lactate clearance is a useful biomarker for the prediction of all-cause mortality in critically ill patients: a systematic review and metaanalysis*. Crit Care Med. 2014;42:2118-25.

26. Jeeyapant A, Kingston HW, Plewes K, Maude RJ, Hanson J, Herdman MT, Leopold SJ, Ngernseng T, Charunwatthana P, Phu NH, Ghose A, Hasan MM, Fanello Cl, Faiz MA, Hien T, Day NP, White NJ, Dondorp AM. Defining surrogate endpoints for clinical trials in severe falciparum malaria. PLoS One. 2017;12:e0169307.

27. Munde A, Kumar N, Beri RS, Puliyel JM. Lactate clearance as a marker of mortality in pediatric intensive care unit. Indian Pediatr. 2014;51:565-7.

28. Rhodes A, Evans LE, Alhazzani W, Levy MM, Antonelli M, Ferrer R, Kumar A Sevransky JE, Sprung CL, Nunnally ME, Rochwerg B, Rubenfeld GD, Angus DC, Annane D, Beale RJ, Bellinghan GJ, Bernard GR, Chiche JD, Coopersmith C, De Backer DP, French CJ, Fujishima S, Gerlach H, Hidalgo JL, Hollenberg SM, Jones AE, Karnad DR, Kleinpell RM, Koh Y, Lisboa TC, et al. Surviving Sepsis Campaign: international guidelines for management of sepsis and septic shock: 2016. Crit Care Med. 2017;45:486-552.

29. Amir A, Saulters KJ, Olum S, Pitts K, Parsons A, Churchill C, Taseera K, Muhindo R, Moore CC. Outcomes of patients with severe sepsis after the first 6 hours of resuscitation at a regional referral hospital in Uganda. J Crit Care. 2016;33:78-83.

30. Theerawit $P, N a$ Petvicharn $C$, Tangsujaritvijit $V$, Sutherasan $Y$. The correlation between arterial lactate and venous lactate in patients with sepsis and septic shock. J Intensive Care Med. 2018;33:116-20.

31. Parsapour K, Pullela R, Raff G, Pretzlaff R. Type B lactic acidosis and insulinresistant hyperglycemia in an adolescent following cardiac surgery. Pediatr Crit Care Med. 2008;9:e6-9.

32. Enoch AJ, English M, Shepperd S. Does pulse oximeter use impact health outcomes? A systematic review. Arch Dis Child. 2016;101:694-700.

33. Garcia-Alvarez M, Marik P, Bellomo R. Sepsis-associated hyperlactatemia. Crit Care. 2014;18:503.

34. Casals-Pascual C, Kai O, Lowe B, English M, Williams TN, Maitland K, Newton CR, Peshu N, Roberts DJ. Lactate levels in severe malarial anaemia are associated with haemozoin-containing neutrophils and low levels of IL-12. Malar J. 2006:5:101.

35. Day NP, Phu NH, Mai NT, Chau TT, Loc PP, Chuong LV, Sinh DX, Holloway P, Hien TT, White NJ. The pathophysiologic and prognostic significance of acidosis in severe adult malaria. Crit Care Med. 2000;28:1833-40.

36. Maitland K, Newton CR. Acidosis of severe falciparum malaria: heading for a shock? Trends Parasitol. 2005;21:11-6.

37. Cecconi M, De Backer D, Antonelli M, Beale R, Bakker J, Hofer C, Jaeschke R, Mebazaa A, Pinsky MR, Teboul JL, Vincent JL, Rhodes A. Consensus on circulatory shock and hemodynamic monitoring. Task force of the European Society of Intensive Care Medicine. Intensive Care Med. 2014:40:1795-815.

38. World Health Organization (WHO). Management of severe malaria: a practical handbook. 3rd ed. Geneva: WHO; 2012

\section{Submit your next manuscript to BioMed Central and we will help you at every step:}

- We accept pre-submission inquiries

- Our selector tool helps you to find the most relevant journal

- We provide round the clock customer support

- Convenient online submission

- Thorough peer review

- Inclusion in PubMed and all major indexing services

- Maximum visibility for your research

Submit your manuscript at www.biomedcentral.com/submit 